\title{
Vestmanviikin balladi Aulis Sallisen Punainen viiva -oopperassa
}

Suomalaisen 1970-luvun taidemusiikin eräänä postmodernina piirteenä on kansanmusiikin käyttö, joko tyylialluusioina tai suoranaisina sävelsitaatteina. ${ }^{1}$ Aulis Sallisen tuotannossa, erityisesti Punaisessa viivassa (1978) nämä monet tyylialluusiot ja sitaatit ovat saaneet huomattavan osan, jopa siten, että niiden on katsottu tekevän hänen musiikistaan liiankin fragmentaarista. Mm. Hannu-Ilari Lampila kirjoittaa Punaisen viivan toisen ensi-illan kritiikissään Sallisen musiikin jakautuvan tasoiksi, jotka luovat teokseen "kirjavan kokonaisvaikutelman" (Lampila 1978).

Sallinen itse toteaa olleensa Pehr Henrik Nordgrenin ohella ensimmäisiä, jotka alkoivat käyttää taidemusiikissa selviä kansanmusiikkivaikutteita. Sallinen oli ennen Punaista viivaa käyttänyt kansanmusiikkisitaatteja mm. jousikvartetossa Aspekteja Peltoniemen Hintrikin surumarssista (1969) sekä Ratsumies-oopperassa (1974), jossa säveltäjän mukaan koko kolmannen näytöksen pohjana on kansansävelmästä - Tuuti lasta tuonelahan - kasvava aihe. (Kulttuurivihkot 2/1979).

Punaisessa viivassa puhdasta kansansävelmää edustaa ainoastaan oopperan kolmanteen kohtaukseen sisältyvä Vestmanviikin balladi, venäläisen kulkukauppiaan Simana Arhippainin laulama säkeistömuotoinen laulu. Sen sijaan kansanmusiikkia muistuttavaa aineistoa ooppera sisältää muutenkin. Oopperan seitsemänteen kohtaukseen sisältyvä Kaisan kehtolaulu, kalevalasävyinen, yksinkertainen melodia, on säveltäjän mukaan kansanmusiikin eleen matkimista ja hyväksi-

\footnotetext{
${ }^{1}$ Kun postmodernismin on katsottu merkitsevän sitä, että usko marxismiin ja muihin samankaltaisiin ns. "suuriin kertomuksiin" on kuollut, ovat musiikin "suuria kertomuksia" Heiniön mukaan mm. usko musiikin lineaariseen kehitykseen: "modernia seuraa vielä modernimpi" sekä usko musiikin kehityksen etenemiseen ei niinkään taideteoksesta toiseen, vaan sävellysteknisestä keksinnöstä toiseen. Postmoderni musiikki elää "traditionalistisen ja modernistisen sävelkielen välimaastossa, niiden jännitteessä, poleemisessa suhteessa molempiin". Musiikissa postmodernismi voidaan nähdä nimenomaan eurooppalaisen modernismin "reaktiona ja jatkeena". Taidekeskustelussa postmodernismi lähti liikkeelle 1970-luvulla arkkitehtuurin piiristä, jossa sen ilmentymänä pidettiin yksiarvoisen yhtenäistyylin tilalle tullutta tyylipluralismia. (Heiniö 1995; 243, 244.) Yhteiskunnallisesti postmodernin on katsottu merkitsevän hyvinvointivaltion tai sosiaalivaltion kriisin jälkeistä "epäjärjestäytyneen kapitalismin yhteiskuntaa" (Ala-Suutari 1996; 253-255).
} 
käyttöä. Sallisen mukaan kansansävelmässä on jotain "äärettömän kristalloitunutta," joka ilmenee siinä, että se on elänyt "ruosteen raiskaamatta satoja vuosia". Kansanmusiikki vaikuttaa säveltäjän mukaan hänen musiikissaan tietynlaisena pohjavirtana, jota voidaan sanoa suomalaisuudeksi, vaikkei hän sitä tietoisesti käyttäisikään. Jokaisen säveltäjän olisi hyvä joskus mennä tällaisille lähteille, "tuon tavattoman kristalloituneen, yksinkertaisen kiteen luo ja katsoa mitä se sisältää". (ibid.)

Vestmanviikin balladin laulaa Punainen viiva -oopperassa laukkuryssä Simana Arhippaini, jonka tulo oopperan kolmannessa kohtauksessa tuo teokseen tervetulleen suvantovaiheen teoksen dramaattisen alun, Riikan ja Topin ankean elämäntilanteen esittelyn ja Topin painajaisunen jälkeen. Toisin kuin Juhani Ahon romaanissa Juha, ja sittemmin myös Leevi Madetojan ja Aarre Merikannon samannimisissä oopperoissa esiintyvä laukkuryssä Uhtuan Shemeikka, jonka vierailusta koko Juha-draama saa pääasiallisen jännitteensä, on venäläinen kulkukauppias Simana Arhippaini Punaisessa viivassa vain taustalle jäävä hahmo, jonka yhteydet teoksen narratiiviseen rakenteeseen ovat löyhähköt. Sallinen on halunnut oopperassaan laajentaa ja korostaa Arhippainin merkitystä hakemalla hänelle oopperan kolmanteen kohtaukseen tekstiä muualta. Näitä tekstejä ovat Arhippainin sekä Topin ja Riikan lasten välinen vuoropuhelu, joka perustuu Kiannon satuun Kaiken kyselijä tyttö (Kianto, 1915) sekä Vestmanviikin balladi, jonka tekstin kuten myös sävelmän on Sallinen lainannut vanhasta samannimisestä kansanballadista.

Vestmanviikin balladin tekstistä on talletettu noin viisikymmentä käsikirjoitusversiota, äänitteitä siitä on saatu vain muutaman kerran. Vestmanviikin (Vesnaviiki, Vensmanviiki, Westmark) balladi on käännös ruotsalaisesta Sven Svanevit-balladista, jonka suomalainen traditio perustuu ainakin osittain arkkijulkaisuun. ${ }^{2}$ Vestmanviikin balladi kuuluu kansainväliseen arvoituslaulustoon, ja sillä on yhtymäkohtia sekä muinaisskandinaavisiin että itämaisiin arvoituslauluihin ja satuihin. Balladin alkuperää ei ole onnistuttu kokonaan selvittämään. Sallisen lähteenä olleen balladin version on laulanut Elimäellä vuonna 1900 syntynyt Martta Pulli. Balladi on äänitetty Kaustisella 1973. Suomalaisen kirjallisuuden seura on tallettanut sen sekä tekstinä, että äänitteenä. (Asplund 1977;3,8.)

\footnotetext{
2 Alunperin balladilla (lat. ballare, tanssia) tarkoitettiin tanssiin säestykseksi laulettua laulua. Balladimuodin katsottiin syntyneen keskiajan Ranskassa, josta se levisi muualle Eurooppaan. Suomenkielisillä alueilla balladin liittymisestä tanssiin ei ole tietoja Inkeriä lukuunottamatta. Balladin juoni etenee tavallisesti dramaattisena dialogina ja päättyy useimmiten päähenkilön kuolemaan. Suomalaiset balladit ovat heterogeeninen perinteenlaji sekä tekstiltään että sävelmiltään. Ensimmäiset balladit saapuivat Suomeen luultavasti 1400-luvun loppupuolella. Perinnettä välittivät lähinnä kaksikieliset henkilöt lännestä päin, mutta myös idästä on saapunut meille balladiaineksia. (Asplund 1977, 4-6).
} 
Pulli:

1. Vestmanviiki tietä ratsasti, jolla hän nuorukaisen kohtasi. Kuulepas sä nuorukainen mitä sanon sul. Taidatkos sä vastata nää kysymykset mul?

3. Vestmanviiki löi hänet miekallaan, että veri tuli hänen kasvoistaan. Vestmanviiki antoi hänet alttiiksi juur niinkuin lehti irtoaa ja putoaapi puust.

5. Olen minä oppinut vastailemaan viisaan järjen antoi mulle Jumala. Jos sä tahdot kysyä ne kysymykset mul, niin mä tahdon vastata ne vastaukset sul.

7. Ajatus sit lintua vikkelämpi on. Synti sitä korppia mustempi on. Enkelit on valkeammat joutsenia, ja ukkonen huutaa kovemmin kuin kurki.

9. Mikä se laviamman sillan rakentaa, jonka alla kalaset ain virras vaeltaa? Mikäs on se niin sangen lavia tie, jota myöten ihmiset ain keviään vaeltaa?
2. En ole oppinut vastailemaan.

Eilen tapoin tämän maan sen Viikin kuninkaan Tapoitko sä tämän maan sen Viikin kuninkaan Silloin sinä tapoit minun veljen.

4. Vestmanviiki tietä ratsasti jolla hän nuorukaisen kohtasi Kuulepas sä nuorukainen mitä sanon sul Taidatkos sä vastata nää kysymykset mul

6. Mikä sitä lintua vikkelämpi on? Mikä sitä korppia mustempi on ? Mitkä ovat valkeammat joutsenia? Ja mikä huutaa kovemmin kuin kurki?

8. Mikä sitä ympyriäistä ympyriäisemp on ? Missä ne kirkkaimmat kynttilät on ? Missä ompi majansa auringolla? ja missä ovat kuoleen miehen jäljet?

10. Aurinko se pyöreä ja ympyriäinen on Taivaalla ne kirkkaimmat kynttilät on. Idäss ompi majansa auringolla. ja haudassa on kuolleen miehen jäljet.

11. Talvi se laviamman sillan rakentaa, Jonka ala kalaset ain virras vaeltaa Helvetin tie on se lavia tie jota myöten ihmiset ain keviäst vaeltaa.

Pullin version alkuun kuuluvan kehyskertomuksen, päähenkilön arvuuttelukohtauksen ensimmäiselle vastaantulijalle ja tämän surmaamisen, (Pullin version kolme ensimmäistä säkeistöä) on Sallinen jättänyt pois. Lisäksi säveltäjä-libretisti on muuttanut joitain yksittäisten sanojen muotoa (8. säkeistö: Pulli: ympyriäistä, Sallinen: ympyrjäistä; 9. säk. Pulli: keviään, Sallinen: keviäst).

Martta Pullin versiossa ei ole suomalaiseen toisintoon tavallisesti kuuluvaa loppukohtausta, jossa arvuuttaja palkitsee vastaajan kultasormuksin. Sen sijaan Jaakko Kivirinnan vuonna 1961 laulamassa toisinnossa "Westmark se tietä myötemme ratsasti" (Ala-Könni 1978,177) esiintyy kehyskertomuksen lopussa myös vastaajan palkitseminen.

1. Westmark se tietä myötemme ratsasti, hän nuorukaisen tiellä kohtasi.

Kuulepas sä nuorukainen mitä sanon sull, taidatkos sä vastata nää kysymykset mull?
2. En ole oppinut vastailemaan, vaan eilen tapoin tämän maan viidennen kuninkaan vai tapoit sinä tämän maan viidennen kuninkaan niin tapoit myöskin veljeni. 
3. Westmark löi hänet alttiiks juur, ett hän kaatui maahan kuin puu. Westmark se edemmäksi ratsasti, hän toisen nuorukaisen kohtasi.

5. Mikä sitä lintua vikkelämpi on, mitkä ovat valkeammat joutsenta, mikä se huutaa kovemmin kuin kurki, mikä ompi mustempi korpin pukua?

7. Mieli sitä lintua vikkelämpi on, enkelit ovat valkeammat joutsenta, ukkonen huutaa kovemmin kuin kurki, synti ompi mustempi korpin pukua.
4. Kuulepas sä nuorukainen mitä sanon sull, Taidatkos sä vastata nää kysymykset mull? en ole minä oppinut vastailemaan, vaan hyvän järjen antoi mulle Jumala. Jos sä taidat kysymykset kysyä, niin ehkä taidan niihin vastata.

6. Mikä sen laveamman sillan rakentaa, jonka alla kalaset virrassa vaeltaa? Mikä se tie on niin kovin leveä, jonka päällä ihminen vaeltaa sangen keveää?

8. Talvi sen laveamman sillan rakentaa, jonka alla kalaset virrassa vaeltaa. Helvetin tie on niin kovin leveä, jonka päällä ihminen vaeltaa sangen keveää.

9. Koska taisit näihin vastata, niin ehkä taidat enemmänkin.

Westmark otti kultasormusta viisi ja antoi ne nuorukaiselle muistoksi.

Kivirannan neljäs säkeistö sisältää kaksi ylimääräistä säettä. Ilmeisesti laulaja on tässä kerrannut melodiaa. Säkeet ovat muutenkin epäsäännöllisen pituisia, joten laulajan on täytynyt lisätä melodiaan myös välisäveliä.

Tekstin lisäksi Sallinen on lainannut Martta Pullin laulamasta toisinnosta myös melodian. Säveltäjä on tasoittanut Pullin toisinnon pisteellisiä rytmejä.

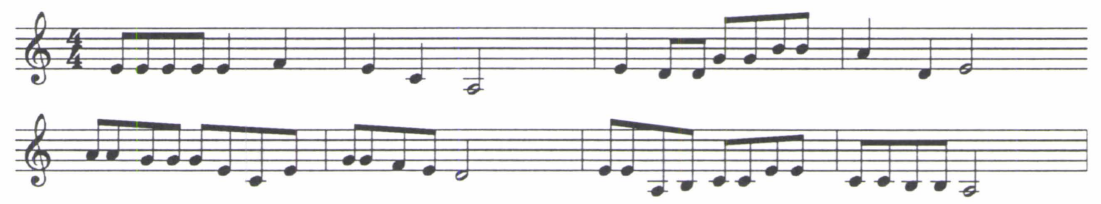

Esimerkki 1. Vestmanviikin balladi, Punainen viiva, tahdit 1238-1245.

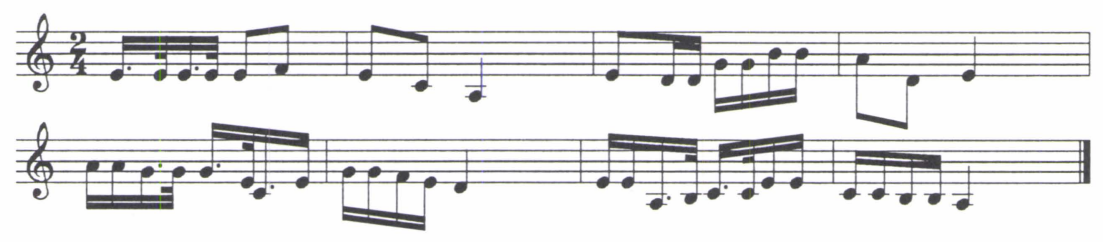

Esimerkki 2. Vestmanviikin balladi, Martta Pullin laulama versio (Asplund 1977,8). Esimerkki on transponoitu a-molliin vertailun helpottamiseksi. Alkuperäinen taltiointisävellaji on d-molli. 


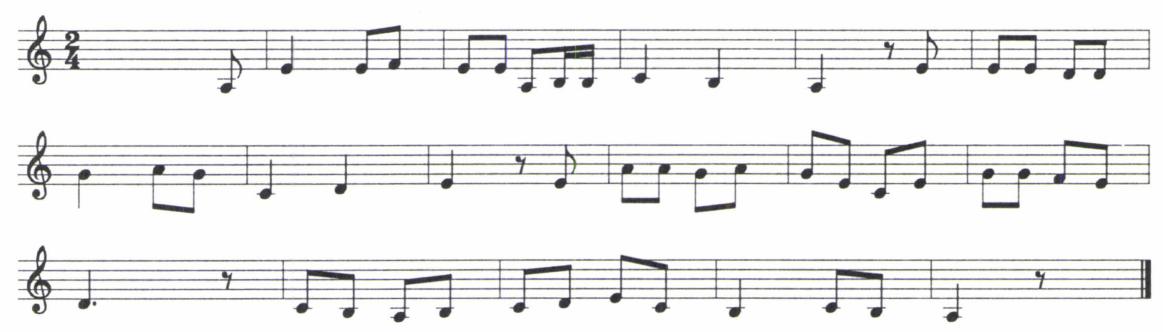

Esimerkki 3. Vestmanviikin balladi, Kivirinnan toisinto. (Ala-Könni 1978,177) Transponoitu a-molliin. Alkuperäissävellaji c-molli.

Vestmanviikin balladi sijaitsee oopperan kolmannessa kohtauksessa Simanan ja Riikan tervehdysten ja lasten esittämien kysymysten jälkeen. Lasten kysymykset sisältyvät Kiannon Turjanlinnan satukirjaan (Kianto 1915) kuuluvaan satuun Kaiken kyselijä tyttö. Kun Kiannon romaani sisältää lapsille kirjoitettuja repliikkejä vain muutaman lähes merkityksettömän lauseen, on Sallinen halunnut muuttaa lasten asemaa pelkkien shokkiefektien aiheuttajista aidoiksi roolihenkilöiksi ottamalla heille tekstiä Kiannon muusta tuotannosta. Vuoropuhelusta Simanan ja lasten välillä kasvaakin koko kolmannen kohtauksen alun päätapahtuma. Lasten esittämien kysymysten "Onko Jumalallakin partaa? Mutta miksei ihminen ulotu aurinkoon asti, että saattaisi paistaa kalaa?" jälkeen Simana toteaa: "Sinähän... Vasta kaiken kyselijä. Mutta nyt on minun vuoroni kysyä! Kuuntelehan." Siirtyminen lasten kysymyksistä Vestmanviikin balladin kysymys-vastaus -dialogiin tapahtuu luontevasti edellä mainitun Simanan repliikin välityksellä.

Balladi sisältää siis kahdeksan säkeistöä (Pullin version säkeistöt 4 -11). Alussa on 5 tahdin mittainen orkesterijohdanto ja kaikki 8 säkeistöä liittyvät toisiinsa pienillä orkesterivälikkeillä. Johdannossa ja välikkeissä Sallinen käyttää kahta, balladin alusta johdettua aihetta. Orkesterijohdannossa ja ensimmäisen ja toisen, kolmannen ja neljännen, sekä viidennen ja kuudennen säkeistön välissä esiintyy aihe, johon on piilotettu balladin alkusävelet. Säkeistöjen välissä esiintyessään aihe on lyhentynyt.

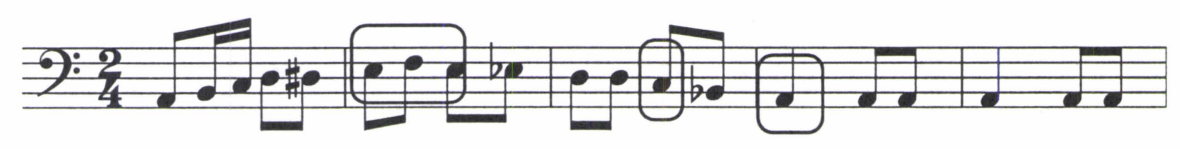

Esimerkki 4. Tahdit 1233-1237. Vestmanviikin balladin orkesterijohdanto, sello, kontrabasso. 
Muiden säkeistöjen välikkeissä esiintyy motiivi joka sisältää ylöspäisen a-mollin suurseptimisoinnun. Tämä motiivi esiintyy aikaisemmin augmentoituna Simanan puhuessa keisarin huolesta tämän kuullessa ihmisten mellakoivan (tahdit 1138-1140 "Ihmiset metelöivät", kts. esimerkki 6) sekä alkuperäisessä muodossaan orkesteritekstissä repliikin yhteydessä. Ylöspäinen suurseptimisointu muuntuu vahvaksi itsenäiseksi aaltomaiseksi motiiviksi Puntarpää-kohtauksen lopussa, jossa agitaattori Puntarpää houkuttelee kansaa äänestämään uutta vasemmistopuoluetta ja toteaa köyhälistön päivänkoiton alkaneen (Esimerkki 7).

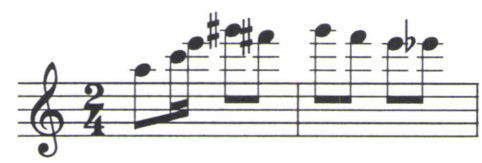

Esimerkki 5. Vestmanviikin balladin orkesterivälike tahdit 1250-1251, huilu.

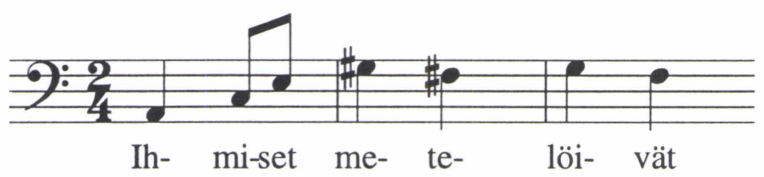

Esimerkki 6. Tahdit 1138-1140. Simana Arhippainin repliikki.

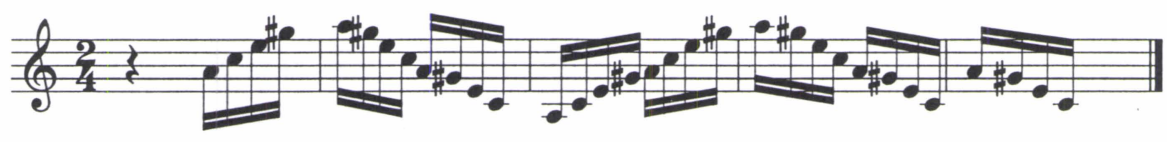

Esimerkki 7. Tahdit 2191-2195. Köyhälistön päivänkoitto -motiivi Puntarpää-kohtauksessa, viulu.

Balladin soinnutuksessa Sallinen käyttää terssi- ja sekuntisuhteisia kolmisointuja, jotka etenevät usein rinnakkaisliikkeessä. Tonaalista vaikutelmaa lisää jokaisen säkeistön alkaminen ja päättyminen puhtaalla - tosin joskus terssittömällä - amollisoinnulla. Säkeistöjen lopun kvarttisuhteisten sointujen kadensaalisuutta on säveltäjä kiertänyt muuntamalla dominanttisoinnun mollimuotoon. 


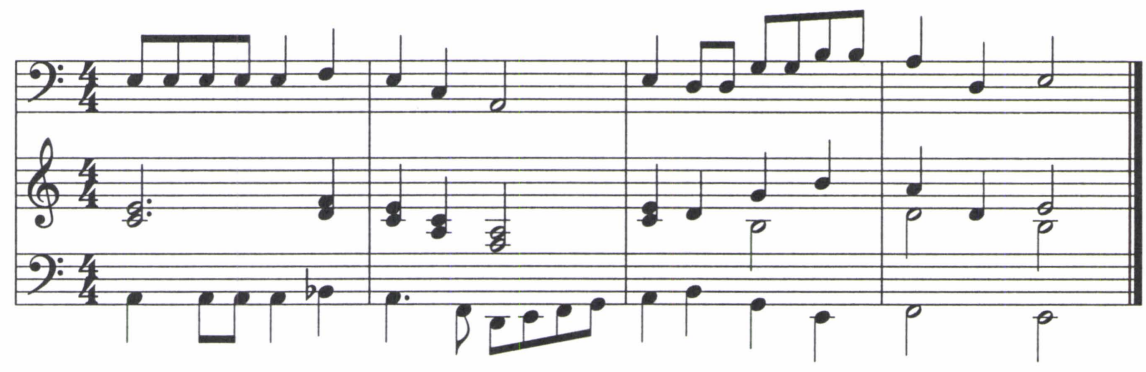

Esimerkki 8. Tahdit 1238-1241 Vestmanviikin balladin alku.

Sallinen on käyttänyt Vestmanviikin balladista muunneltuja aiheita koko kolmannen kohtauksen kantavina motiiveina. Jo kohtauksen alun orkesterijohdanto sisältää balladin suoran inversion, jonka säveltäjä on hajoittanut kahteen oktaavialaan trumpetille ja huilulle. Orkesterijohdanto, joka on samalla Arhippainin sisääntulomusiikki, muodostaakin rytmisesti ja melodisesti profiloituine selkeine linjoineeen vahvan kontrastin oopperan alun tritonuspohjaiselle, rytmisesti häilyvälle ja tummasävyiselle sävelmaalailulle. Johdannossa esiintyvä inversio ei esiinny koskaan yhtäaikaa balladin kanssa vaan inversio on saanut kolmannen kohtauksen alussa kohtauksen tunnelmaan johdattavan itsenäisen tehtävän.

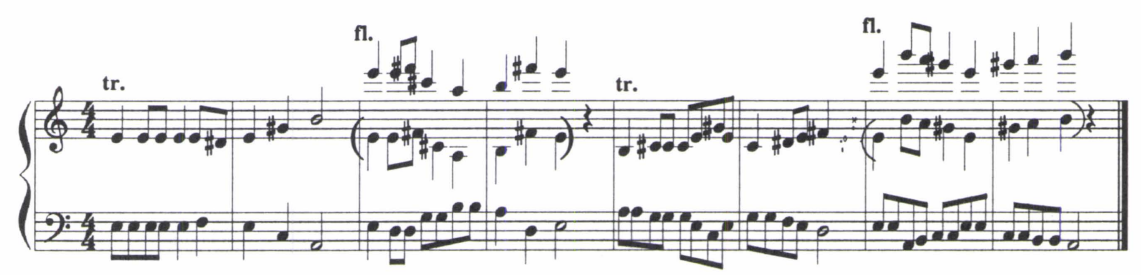

Esimerkki 9. Vestmanviikin balladi (tahdit 1238-1245) ja sen inversio (tahdit 940-947).

Myöhemmin kolmannessa kohtauksessa Sallinen käyttää inversion kahta ensimmäistä tahtia, Arhippainin tulomotiivia vaihtelevissa diminuutiomuodoissa, jolloin kohtauksen tunnelma tihenee kohti kohtauksen päättävää marssia, joka ennakoi ja valmistaa koko oopperan rakenteen ja sanoman kannalta keskeistä Puntarpää- kohtausta. Kolmannen kohtauksen päätösmarssi sisältääkin lähinnä Arhippainin tulomotiivin muuntelua ja päätösmarssiin alkuaihe on Arhippainin tulomotiivin suora diminuutio. Aiemmin kohtauksessa Arhippainin tulomotiivi esiintyy myös usein triolimuotoisena (kts. esimerkki 12). 


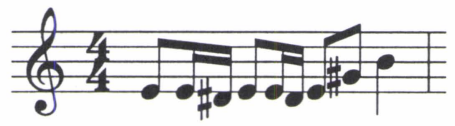

Esimerkki 10. Tahti 1609. 3. kohtauksen päätösmarssin alku, trumpetti.

Vaikka Punaisen viivan homofoninen ja runsaasti repetitiota sisältyvä sävelkudos ei juurikaan sisällä yhtäaikaisia motiiveja, esiintyy Arhippainin tulomotiivi eräiden muiden motiivien kanssa yhtäaikaisesti. Näitä ovat Arhippainin hyräilymotiivi, jonka Arhippaini laulaa useimmiten a bocca chiusa. Keisarimotiivi, jonka yhteydessä Arhippaini kuvailee keisaria armolliseksi isäksi ja auringoksi, esiintyy yhdessä Arhippainin tulomotiivin kanssa.

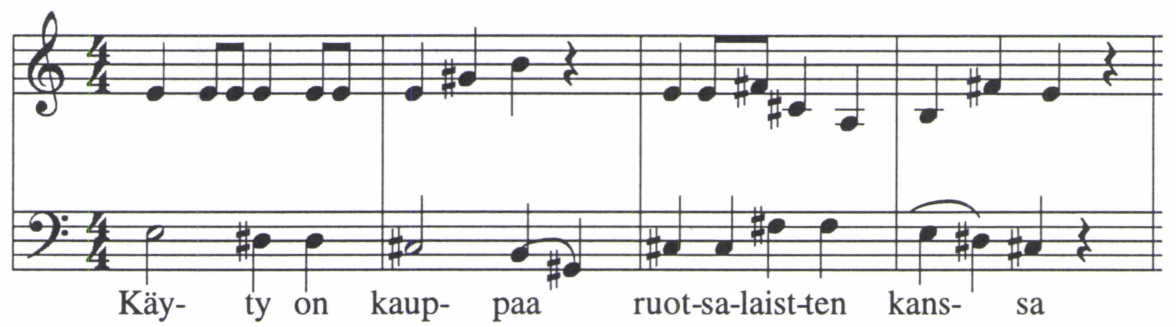

Esimerkki 11. Tahdit 972-975, Arhippainin tulomotiivi ja hyräilymotiivi.

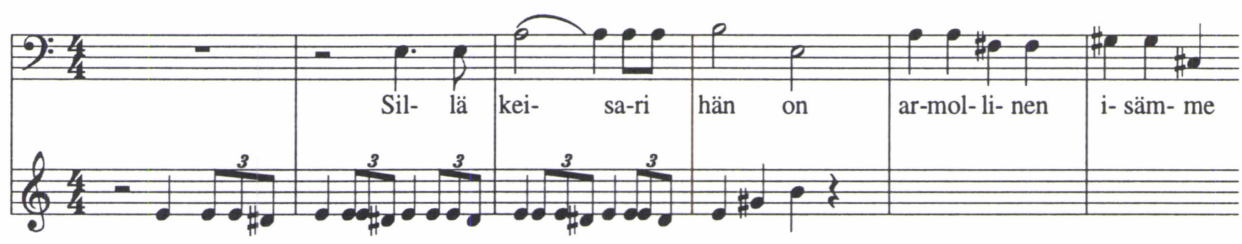

Esimerkki 12. Tahdit 1088-1093, Arhippainin tulomotiivin triolimuunnos ja keisarimotiivi.

Kun tarkastellaan Arhippainin yhteyttä oopperan juoneen pelkän tekstin avulla, on yhteys ilmiselvän hatara, ja onkin kysyttävä, onko Arhippainilla lainkaan tehtävää koko oopperassa. Sadunomainen kysymys-vastaus -dialogihan ei liity millään tavalla oopperan kokonaisjuoneen, uuden aatteen leviämiseen ja sen mahdollisesti aiheuttamiin parannuksiin syrjäseudun ihmisten elämässä. Simana Arhippainin funktio Kiannon romaanissa on selvempi. Siellä Simana tuo Topin pirttiin tullessaan mukanaan kirjan "Kansalaisen vaaliopas", joka sisältää puolu- 
een antamia äänestysohjeita. Kansalaisen vaaliopas on romaanissa sikäli merkittävä, että vasta se saa Riikan uskomaan tulossa oleviin vaaleihin, Topin puheisiin hän ei ole luottanut (Kianto 1958; 107-110). Sallinen on jättänyt libretostaan pois kirjan tuomisen, mutta Arhippainilla on kuitenkin oopperassa tehtävä; hän tuo ensimmäistä kertaa Topin pirttiin tiedon tulossa olevista mullistuksista. Simana ei kuitenkaan ilmaise asiaa suoraan vaan replikoi: "Keisarilla ei ole helppoa nykyään, Ihmiset metelöivät, kokoontuvat, rähinöivät, lakkoilevat kapinoivat." (tahdit 1130-1154.) Kun tekstiyhteydet rajoittuvat pelkkien vihjailujen tasolle, on Arhippainin roolia korostettu musiikillisten viittausten avulla. Arhippainin sävelmotiiveissa on selvä yhteys niin Suutariin ja Suutarin Kunillaan kuin Agitaattori Puntarpäähänkin, jotka kaikki kuuluvat oopperassa henkilöihin, jotka tuovat tietoa uudesta aatteesta. (Anttila 1995; 61-63,71,95.) Tämä yhteys näkyy mm. hyräily-motiivissa, jota Arhippaini hyräilee a bocca chiusa myötäillen Suutarin repliikkiä tämän kehottaessa Topia ja Riikaa tulemaan väenkokoukseen, jossa agitaattori Puntarpää kertoo uudesta aatteesta (tahdit 1595-1608). Hyräilymotiivi jatkuu myös vallankumouksellista tunnelmaa nostattavan 3. kohtauksen päätösmarssin yhteydessä, kuvastaen Arhippainin uudelle aatteelle myötämielistä asennetta (tahdit 1609-1610). Suora viittaus Arhippainista Puntarpäähän syntyy jo aiemmin esitellyn köyhälistön päivänkoitto -motiivin välityksellä.

Kun fragmentaarisuuden todettiin olevan eräs Punaisen viivan musiikin hallitsevin ominaispiirre, on säveltäjä yhtenäistänyt teoksen tyylillistä hajanaisuutta rakentamalla oopperan temaattisen materiaalin noudattamaan orgaanisen kasvun periaatteita alkaen yhdestä musiikillisesta perusideasta. Tämä ns. deduktiivinen motiivitekniikka (kts. Heiniö 1995; 65), joka on eräs 1900-luvun sinfonisen sävellystekniikan perusperiaatteita, merkitsee Punaisen viivan kolmannessa kohtauksessa sitä, että kohtauksen musiikillinen materiaali on johdettu pääasiallisesti Vestmanviikin balladista. Balladi on siten koko kolmannen kohtauksen musiikillinen alkusolu. Samanlainen työskentelytapa on havaittavissa myös teoksen muiden melodiasitaattien käytön yhteydessä. Mm. oopperan neljänteen kohtaukseen sisältyvä sävelsitaatti, vanha työväenmarssi, Barrikaadimarssi ${ }^{3}{ }^{3}$ saa osakseen hyvin samankaltaisen käsittelyn.

\section{Lähteet}

Ala-Könni, Erkki (toim.). 1978. Alavuden laulukirja. Tampereen yliopiston kansanperinteen laitos.

Alasuutari, Pertti. 1996. Toinen tasavalta, Suomi 1946-1994. Tampere: Vastapaino.

\footnotetext{
${ }^{3}$ Tämä vanha venäläinen marssi, joka julkaistiin Suomessa ensimmäisen kerran vuonna 1917, sisältyy mm. Pekka Gronowin toimittamaan työväenlaulukirjaan (Gronow 1979; 39, 40).
} 
Anttila, Jarmo 1995. Musiikki, rakenne ja funktio. Struktuurianalyysi Aulis Sallisen oopperasta Punainen viiva. Pro gradu -tutkielma. Jyväskylän yliopiston musiikkitieteen laitos.

Asplund, Anneli 1977. Suomalaista kansanmusiikkia I. Balladeja. Suomalaisen kirjallisuuden seura. Helsinki. Julkaisuun liittyvä samanniminen äänite Finnlevy SFLP 8551.

Gronow, Pekka 1979. Laulukirja, Työväen lauluja kahdeksalta vuosikymmeneltä. Helsinki: Tammi.

Heiniö, Mikko 1995. Suomen musiikin historia 4. Aikamme musiikki 1945-1993. Porvoo: WSOY.

Kianto, Ilmari 1915. Turjanlinnan satukirja. Helsinki: Otava.

Kianto, Ilmari 1958. Punainen viiva. Helsinki: Otava.

Kulttuurivihkot. 2/1979. Ilman kirjoittajan nimeä. Punainen viiva, ooppera kaikille, kaikille, kaikille... .

Lampila, Hannu-Ilari 1978. Sallisen oopperan musiikin tasot. Helsingin sanomat 4.12.1978.

Sallinen, Aulis. Punainen viiva, orkesteripartituuri, moniste. Suomalaisen musiikin tiedotuskeskus /Novello. 